\title{
Effects Of Teachers' Questioning Strategies On Students' Achievement In Social Studies In Obio-Akpor Local Government Area Of Rivers State, Nigeria
}

\author{
Dr. Ijeoma Margaret Opara \\ Department of Educational Psychology, \\ Guidance and Counselling, Faculty of Education, \\ University of Port Harcourt, Nigeria. \\ Ajike Afor Uma \\ Department of Educational Psychology, \\ Guidance and Counselling, Faculty of Education, \\ University of Port Harcourt, Nigeria.
}

\begin{abstract}
The study investigated the effects of teachers' questioning strategies on students' achievement in Social Studies in Obio-Akpor Local Government Area of Rivers State, Nigeria. Four research questions and four null hypotheses guided the study. The study adopted quasi-experimental research design. A sample of one hundred and twenty (120) male and female JS3 students from three (3) intact classes A, B, and C in the ratio of 40:40:40 respectively using stratified and purposive sampling techniques were used for the study. The instrument used for the study was titled Social Studies Achievement Test (SSAT). The instrument was validated by subject specialists and measurement and evaluation experts based on content and face validities. The reliability of the instrument was determined using Kuder-Richardson 20 formula and the reliability coefficient obtained was 0.87 . Mean and standard deviation were used to answer the research questions while t-test and Analysis of Variance (ANOVA) were used to test the hypotheses at 0.05 alpha level. The result revealed that convergent and divergent questioning strategies significantly had effects on students achievement in Social Studies, while gender had no significant effect. Based on these findings, it was recommended among others that teachers should pay more attention to their questioning strategies because they are frequently used tools and the way to good teaching.
\end{abstract}

Keywords: Convergent, divergent, questioning strategies, Social Studies, and Achievement.

\section{INTRODUCTION}

Academic achievement refers to what a student has achieved in different subjects of study. Kumara (2001) defined academic achievement as the sum total of information gained after completing a course of instruction (partially or fully) while is measurable with the use of achievement test. Academic achievement is the overall academic performance of students in the school. Academic achievement has been seen as the educational goal that is achieved by students, teachers or institutions over a period of time. Generally, academic achievement may be assessed by the use of achievement tests. Achievement is reflected by the extent to which skill or knowledge has been acquired by a person through the training imparted to him. If our educational system is to prepare young people adequately for challenges and demands of $21^{\text {st }}$ century, then academic achievement should not be downplayed (Ogbonna, 2014).Opara, Nwaukwu and Magnus-Arewa, (2018) opined that academic achievement is measured using different means and methods and approaches which ultimately result in high, low or average 
performance. In secondary schools, a student's academic achievement determines his progress in his studies and justifies or quantifies him to move to the next level.Christopher (2011), opined that academic achievement helps to screen or diagnose students current level of academic functioning as well as the extent to which they have acquired the knowledge and skills more than their counterparts of the same age or class.

However, most teachers do not appreciate their roles in the classroom and these invariably affect the quality of teaching and learning in the educational system. Apparently the teachers have been blamed for not improving students' achievement in social studies due to lack of appropriate teaching techniques. Some teachers use traditional approach of teaching which hamper the improvement of the learners. Some still employ the laissez fair approach of teaching which makes the achievement of students to be flexible while others employ democratic approach of teaching which can be considered as the ideal approach of teaching because it creates room for questions and classroom interaction. In juniorsecondary schools, different subjects are taught including Social Studies.

Social studies is the integrated study of the social sciences, humanities and history. Within the school program, social studies provide coordinated, systematic study drawing upon such disciplines as anthropology, archeology, economics, geography, history, political science psychology as well as appropriate content from the humanities, mathematics and natural sciences. Social studies deal with the study of man his relationship with other men and the environment. National council of social studies (1994) defines social studies as the integrated study of the social sciences and humanities to promote civic competence. Therefore, social studies is the study of man and his environment. The primary purpose of social studies is to help young people to make informed and reasoned decisions for the public as good citizens of a culturally diverse, democratic society in an interdependent world.

Social studies is one of the compulsory subjects at the junior secondary schools in Nigeria. This is to implement the National Policy on Education which came into being in 1981. This policy stipulates the teaching of social studies in primary, secondary and all the conventional colleges of education while few universities offer Social Studies as a course (Federal Republic of Nigeria 2004).The problem confronting Social Studies in Rivers State particularly in Obio-Akpor Local Government Area are the absence of related instructional materials, lack of trained social studies teachers, good teaching approaches, methods and techniques and lack of motivation. In view of this situation, the teaching and learning of social studies tends to be ineffective. In the schools, non-specialists teachers are employed to teach socials studies and they apply the traditional methods of teaching subjects like history, geography, economics, government and civics neglecting the essential points or objectives of social studies. Uka (2007) opined that an effective teaching brings about effective learning because for teaching learning process to occur, the teacher must possess those qualities that bring about effective teaching. Hence, the preparation, the strategy and medium through which the learning experiences are communicated must be suitable with the need of the learner. Unaka, (2006) states that teachers' quality depends on the application of various teaching strategies which promote students' interest. Teaching strategy is a method or techniques employed by a teacher to improve or make teaching to be unique and simple to the learner. However, there are several methods of teaching employed in the classroom. It is essential for any teacher mostly social studies teachers to become acquainted with teaching strategies that will enable learners achieve their learning outcome (Unaka 2006).

There are many forms of teaching strategies which questioning technique is one. Questioning technique is a key technique in lesson presentation. It helps to determine the entire behaviour 
of the learners as well as diagnose area of strengths and weaknesses with a view to effecting necessary remedial measures. It is used to develop in the learner the spirit of inquiry, critical thinking and decision making ability. Questioning technique, if used properly is an effective technique that helps to produce a positive interactive classroom. Uzoafia (2007) states that effective teaching and learning take place only when there is interaction. This means communication is the heart of teaching. Therefore, the use of questioning strategies by teachers in their instructions will help to arouse the interaction with the students. Such strategies include divergent and convergent questioning techniques of teaching.

Divergent question is a question with no specific answer but require one's ability to think broadly about a particular topic. Divergent questioning techniques tend to generate new and original solution to problems for those involved in an exercise. It is the process of creating several unique solutions intending to solve a problem. Uka (2007), states that the act of thinking refers to mental manipulation of concepts, rules and precepts. Inductive reasoning going from specific facts to general principle is much like divergent thought. Divergent thinking produces many ideas or alternative ideas. When thinking in a divergent manner, many possibilities are developed from one starting point. Erickson (2007) opined that divergent questions allow students to explore different avenues and create many different variations and alternative answers or scenarios. Correctness may be based on logical projections, contextual, or arrived at through basic knowledge, conjecture, inference, projection, creation, intuition, or imagination. Divergent question often requires students to analyze, synthesize, or evaluate a knowledge base and then project or predict different outcomes. Divergent question is an open ended question that stimulates students' creative thinking, encouraging students to be better observers, discover information by themselves, analyze data, make inferences, and identify relationships. Examples of divergent questions are what is culture? Write down as many types of social groups you know. Convergent thought is the process of finding one best solution to a problem. It is directed towards finding one correct or best answer. Uka (2007) refers to convergent questioning technique as conventional thinking in the problem solving process. It is the ability to give correct or single answer to a problem or question. According to Williams (2003), many tests that are used in schools such as multiple-choice tests, quizzes and standardized tests are measures of convergent thinking. For example, how many aspects of culture do we have? Generally, an effective teacher starts with convergent questions and moves toward divergent questions. These two questioning strategies are opposite to each other. They both play a key role in the reactive problem solving process (Jackson \& Sinclair, 2005). Because the students need to seek novel associations, finding connections between each idea and bridging these thoughts in order to develop new thoughts, they are more interested in divergent questioning strategies.

Also the conventional questioning method of teaching is the oldest method used in teaching which is talk and chalk method. The teacher presents the topic in an orderly and systematic manner suitable to the level of the students and at pace that will not put them under stress. The students listen, ask and answer questions directed to them. According to Uka (2007), conventional questioning method of teaching which is talk and chalk or recitation method is when teacher occupies the centre of the class talks, and uses chalkboard to communicate with students, ask a number of questions so as to determine whether or not learners know what they have been taught. The recitation method is a didactic mode of teaching. It is a way of dispensing facts to the learner. It is generally characterized by excessive teacher control and student passivity. Teacher out talks their students to the detriment of the later in view of all that have been said on questioning strategies, the researchers deemed it necessary to investigate the effects of convergent and divergent questioning strategies of teaching on students' achievement in social studies. 


\section{Research Questions}

The following research questions guided the study

1. What is the effect of convergent questioning strategy on students' achievement in social studies with respect to their pretest-posttest mean scores?

2. What is the effect of divergent questioning strategy on students' achievement in social studies with respect to their pretest-posttest mean scores?

3. To what extent do achievement mean scores of students in social studies differ in the three groups (convergent, divergent and control group)?

4. To what extent do achievement mean scores of male and female students differ in the three groups (convergent, divergent and control group)?

\section{Hypotheses}

The following hypotheses were tested at 0.05 alpha level.

1. There is no significant effect of convergent questioning strategy on students' achievement in social studies with respect to their pretest-posttest mean scores.

2. There is no significant effect of divergent questioning strategy on students' achievement in social studies with respect to their pretest-posttest mean scores.

3. There is no significant difference in the achievement mean scores of students in social studies in the three groups (convergent, divergent and control group).

4. There is no significant difference in the achievement mean scores of male and female students in the three groups (convergent, divergent and control group).

\section{METHODS}

The study was quasi-experimental and it employed a pretest, posttest non-equivalent control group design. Intact classes were randomly assigned to treatments and control group respectively. There were two experimental groups and one control group. The diagram for the design is shown below:

$\mathrm{G}_{1}$

$\mathrm{G}_{2} \quad-$

$\mathrm{G}_{3} \quad-------\rightarrow \mathrm{T}_{1}-\mathrm{T}_{2}$

Where:

$G_{1}-G_{3}$ represent group 1 to $3, T_{1}$ represents the pretest $T_{2}$ represents the posttest $X_{1}$ and $X_{2}$ stand for the treatments (convergent and divergent questioning teaching methods) and represents the control group. The population of the study was 5,000 junior secondary school three (JS3) students of public secondary schools in Obio-Akpor Local Government Area of Rivers State. A sample of one hundred and twenty (120) male and female JS3 students from three (3) intact classes A, B and C in the ratio of 40:40:40 respectively. Using stratified and purposive sampling techniques was used for the study. The instrument used for the study was titled Social Studies Achievement Test (SSAT). It was developed by the researchers and consisted of thirty (30) multiple choice items. The instrument was validated by subject specialists and measurement and evaluation experts based on content and face validities. The reliability of the instrument was determined using Kuder Richardson 20 formula and reliability coefficient obtained was 0.87 .

After the grouping of students, the instrument was administered to them as pretest. After the pretest, social studies exercises based on culture, family and socialization were taught by regular social studies teachers for three weeks using appropriate questioning strategies for the groups. Group A was taught with convergent questioning, group B with divergent questioning and group C control group with conventional questioning method sometimes called teacher 
centered instructional approach. The researchers supervised the questioning strategies in the three groups. After the treatment, a post-test was administered to the three groups. The lesson plan and the instrument were prepared from the social studies content unit of JS3 social studies curriculumMean and standard deviations were used to answer the research questions while t-test was used to test hypotheses 1 and 2 and two-way analysis of variance was used to test hypotheses 3 and 4 at 0.05 alpha level.

\section{RESULTS}

Research Question 1: What is the effect of convergent questioning strategy on students' achievement in social studies with respect to their pretest-posttest mean score?

Hypothesis 1: There is no significant effect of convergent questioning strategy on students' achievement in social studies with respect to their pretest-posttest mean score.

Table 1: Mean, standard deviation and t-test analysis of effect of convergent questioning strategy on students' achievement in Social Studies with respect to their pretest-posttest mean score.

\begin{tabular}{llllllll}
\hline Test & $\mathbf{N}$ & $\bar{X}$ & SD & df & t-cal & Sign & Result \\
\hline Pretest & & 16.00 & 3.46 & & & & \\
Posttest & 40 & 21.88 & 3.37 & 37 & 17.28 & 0.000 & Significant \\
\hline
\end{tabular}

Table 1 showed that pretest mean score is 16.00 with standard deviation of 3.46 , while the posttest mean score is 21.88 with standard deviation of 3.37. It is obvious that posttest mean score is higher than the pretest mean score. This implies that convergent questioning strategy has positive effective on students achievement in social studies.

The table also revealed that the calculated t-value of 17.28 with degree of freedom of 39 was significant at 0.000 . Since the p-value $(0.000)$ is less than the chosen alpha of 0.05 , the null hypothesis of no significant effect of convergent questioning strategy on students' achievement is rejected. Therefore, convergent questioning strategy has a significant effect on students' achievement in social studies.

Research Question 2: What is the effect of divergent questioning strategy on students' achievement in Social Studies with respect to their pretestposttest mean score?

Hypothesis 2: There is no significant effect of divergent questioning strategy on students' achievement in Social Studies with respect to their pretestposttest mean score.

Table 2: Mean, standard deviation and t-test analysis of effect of divergent questioning strategy on students' achievement in social studies with respect to their pretest-posttest mean score.

\begin{tabular}{llllllll}
\hline Test & $\mathbf{N}$ & $\bar{X}$ & SD & df & t-cal & Sign & Result \\
\hline Pretest & & 15.58 & 3.15 & & & & \\
Posttest & 40 & 25.65 & 3.21 & 39 & 14.16 & 0.000 & Significant \\
\hline
\end{tabular}

Table 2 revealed that the mean and standard deviation of the students' pretest are 15.58 and 3.15 respectively. While the posttest mean and standard deviation are 25.65 and 3.21 respectively. It is obvious that the posttest mean score in divergent group is higher than their pretest mean score. This implies that divergent questioning strategy has positive effect on students' achievement in Social Studies. Also, the calculated t-value is 14.16 and the p-value is 0.000. Therefore, since the p-value is less than 0.05 , the null hypothesis was rejected and alternatives retained. This means that divergent questioning strategy has significant effect on students' achievement in Social Studies. 
Research question 3: To what extent do achievement mean score of students' in Social Studies differ in the three groups (convergent, divergent and control group based on their posttest.

Hypothesis 3: There is no significant difference in the achievement mean scores of students in Social Studies in the three groups (convergent, divergent and control group).

Table 3: Mean, standard deviation and one way analysis of variance of the posttest achievement mean scores of students' in social studies in the three groups.

\begin{tabular}{lllllll}
\hline Groups & $\mathbf{N}$ & $\bar{X}$ & SD & Sig & F & Result \\
\hline Convergent & 40 & 21.88 & 3.36 & 0.000 & & \\
Divergent & 40 & 25.65 & 3.21 & 0.000 & 70.08 & Significant \\
Control & 40 & 16.83 & 3.45 & 0.000 & & \\
\hline
\end{tabular}

Table 3 revealed that mean and standard deviation values for students in convergent group were 21.88 and 3.36 respectively, mean and standard deviation for students in divergent group were 25.65 and 3.21 respectively. On the other hand, mean and standard deviation for students in control group were 16.83 and 3.45 respectively. This shows that the divergent group had the highest mean score, followed by convergent group lastly the control group. This implies that there is positive difference in achievement score of students in Social Studies in the three groups.

The calculated F-value of 70.08 and p-value of 0.000 was realized. Since p-value is less than probability level of 0.05 , the null hypothesis is rejected and the alternative retained. This meansthat there is a significant difference in the achievement scores of students in Social Studies in the three groups.

Research question 4: To what extent do achievement mean scores of male and female students differ in the three groups (convergent, divergent and control group).

Hypothesis 4: There is no significant difference in the achievement mean scores of male and female students in the three groups (convergent, divergent and control group). 
Table 4: Mean, standard deviation, and two-way ANOVA for effects of convergent, divergent and conventional questioning strategies in social studies achievement among male and female as shown by their test scores.

\begin{tabular}{|c|c|c|c|c|c|c|}
\hline Groups & Test & $\mathbf{N}$ & $\bar{X}$ & SD & & \\
\hline \multirow[t]{2}{*}{ Convergent } & Male & 15 & 21.27 & 3.59 & & \\
\hline & Female & 25 & 21.64 & 3.28 & & \\
\hline \multirow[t]{2}{*}{ Divergent } & Male & 18 & 25.33 & 3.73 & & \\
\hline & Female & 22 & 25.91 & 2.79 & & \\
\hline \multirow[t]{2}{*}{ Conventional } & Male & 21 & 17.23 & 3.71 & & \\
\hline & Female & 19 & 16.37 & 3.17 & & \\
\hline \multicolumn{7}{|c|}{ Tests of Between-Subjects Effects } \\
\hline Source & $\begin{array}{l}\text { Type III sum } \\
\text { of squares }\end{array}$ & df & $\begin{array}{l}\text { Mean } \\
\text { square }\end{array}$ & $\mathbf{F}$ & Sig & Result \\
\hline Corrected model & 1585.958 & 5 & 316.592 & 27.875 & .000 & \\
\hline Intercept & 53837.387 & 1 & 53837.387 & 4740.297 & .000 & \\
\hline Group & 1560.015 & 2 & 780.007 & 68.678 & .000 & Significant \\
\hline Gender & 2.752 & 1 & 2.752 & .242 & .623 & $\begin{array}{l}\text { Not } \\
\text { significant }\end{array}$ \\
\hline Group * gender & 11.830 & 2 & 5.915 & .521 & .595 & $\begin{array}{l}\text { Not } \\
\text { Significant }\end{array}$ \\
\hline Error & 1294.742 & 114 & 11.357 & & & \\
\hline Total & 5890.000 & 120 & & & & \\
\hline Corrected total & 2877.700 & 119 & & & & \\
\hline
\end{tabular}

Table 4 revealed that mean and standard deviation of male and female in convergent group are $21.27,3.59$ and $21.64,3.28$ respectively. Also the mean and standard deviation of male and female in divergent group are 25.33, 3.73 and 25.91, 2.79 respectively. This implies that female performed better than the male in convergent and divergent groups. While in conventional group (ie control group) male performed higher than their female counterpart. This could be as a result of sample error. Therefore, gender makes no difference in achievement scores of students in social studies.

The table also showed that there was a significant effect of questioning strategies in the achievement of male and female students in Social Studies. The F-calculated value of 68.68 was significant at $0.000 \mathrm{p}$-value which is less than 0.05 alpha level. on the influence of gender on students' achievement in Social Studies using the questioning strategies, the result revealed that the F-calculated value of 0.521 with p-value of 0.595 which was greater than 0.05 alpha level indicated that there was no significant difference in the mean post-test achievement scores of male and female students' in Social Studies test.

\section{DISCUSSION OF FINDINGS}

The discussion of findings of this study was based on the results of the research questions stated and the null hypotheses formulated and tested. For effect of convergent questioning strategy on students' achievement in Social Studies, result obtained revealed that convergent questioning strategy had a positive significant effect on students' achievement in Social Studies. This result is in line with Ifeanacho and Osuagwu (2016) who found out that using convergent instructional method significantly increases academic achievement of students. The result also revealed that divergent questioning strategy has significant effect on students' achievement in Social Studies. This result is in agreement with Ifeanacho and Osuagwu (2016) 
who found out that divergent instructional method significantly increases academic achievement of students.

Again the result showed that there is a significant difference in the achievement scores of students in Social Studies in the three groups. In comparing the performance of students in the three groups, it was observed that students exposed to divergent questioning strategy performed better, followed by convergent group and lastly the control group.

Lastly, the result revealed that there was no significant difference in the mean post-test achievement scores of male and female students in Social Studies. In convergent and divergent female performed better than male. This result however implies that female students pay more attention or has the capability of coping with Social Studies related courses more than their male counterpart. The difference in the achievement scores of male and female students in social studies is statistically insignificant. The finding however is in line with the finding of Ifenacho and Osuagwu (2016) who found out that there was no significant difference in the mean achievement scores of male and female students taught mathematics using convergent and divergent methods. This implies that both male and female students can perform well in any subject if well exposed to different questioning strategies.

\section{CONCLUSION}

The findings of the study indicated that convergent and divergent questioning strategies have significant effects on students' achievement in social studies. Again, that there was no significant difference in the mean post-test achievement scores of male and female students in relation to convergent and divergent questioning in Social Studies. Therefore, teachers should ask questions from simple to complex.

\section{RECOMMENDATIONS}

Based on the findings, the following recommendations were made:

1. Teachers should pay more attention to their questioning strategies because they are frequently used tools and the way to good teaching.

2. Teachers should endeavour to give students questions from convergent ie direct questions and then moves towards divergent questions (ie indirect questions).

3. Students should welcome different questioning strategies as valuable tools for effective learning and ways to effective classroom interaction.

\section{References}

Christopher H. (2011). Family psychodynamics. London: McMillian Publishers.

Erickson, H.L. (2007). Concept-based curriculum and instruction for the thinking classroom. Thousand Oaks: Corwin Press.

Ifeanacho, A.O. \&Osuagwu, C.T. (2016). Effect of convergent and divergent methods of teaching on students mathematics achievement in senior secondary schools in Umuahia Education Zone. ASSEREN Journal of Educational Research and Development (AJERD) 3, 79-87.

Jackson, H. \& Sinclair, C. (2005).Anxiety and educational achievement.Australlia: John Wiley and Sons. Kumara, S.H. (2001). Strategies for producing instructional materials.Owerri: Joewam Publishers. National Council for Social Studies (1994). NCSS task force for teaching and learning of social studies. Ogbonna, K.I. (2014). Emotional intelligence and learning styles as predictors of students' academic achievement.Nigerian Journal of Empirical Studies in Psychology and Education. 1(14); 39-46.

Opara, I.M., Nwaukwu C. \& Magnus-Arewa, E.A. (2018).Psychological variables and emotional intelligence as predictors of students' academic achievement in mathematics in Rivers State, Nigeria.International Journal of Multidisciplinary Research and Development 5(4), 13-20. 
Uka, C.U. (2007). Effects of conventional and cooperative learning strategies on the academic performance of senior secondary school economics students.Unpublished M.Ed theses.Abia State University.

Unaka, C.F.N. (2006). Effect of instructional strategies on students' achievement in Biology.Unpublished M.Ed theses, University of Port Harcourt.

Uzoafia, L. (2007). Effect of using mathematics laboratory in teaching mathematics on students' achievement in mathematics.Unpublished M.Ed Theses.Abia State University

Williams, Y. (2003). Convergent thinking: definition, examples of quiz, Education Portal. 